Research article

\title{
Bioprospecting fungal diversity from crude oil infiltrate soil of
} Assam, India's Northeast

\author{
N. F. Islam* \\ Department of Botany, N.N. Saikia College, Titabar-785630, Jorhat, Assam, India \\ *Corresponding Author: nazimforidislam@yahoo.co.in \\ [Accepted: 22 August 2017]
}

\begin{abstract}
The Screening of native fungi from crude oil contaminated soil of Assam is conducted. Total crude oil concentrations varied from $39000 \mathrm{mg} \cdot \mathrm{Kg}^{-1}$ to $51500 \mathrm{mg} \cdot \mathrm{Kg}^{-1}$. The soil fungal population varied from $14.6 \times 10^{6} \mathrm{CFU} \cdot \mathrm{g}^{-1}$ to $19.2 \times 10^{6} \mathrm{CFU} \cdot \mathrm{g}^{-1}$ soil. Twenty fungal strains were isolated and out of them seven were selected on the basis of their ability to grow in PDA medium where crude oil is used as sole carbon source. The growth rate and tolerance of each strain to crude oil were examined and were found quite satisfactory. The radial extension rate varied from 0.03 $\mathrm{cm} \cdot \mathrm{d}^{-1}$ to $0.50 \mathrm{~cm} \cdot \mathrm{d}^{-1}$ and exhibited significant differences $(P<0.01)$ among the selected strains. The degradation percentage of crude oil was in the range of $71 \%$ to $89 \%$ in mineral salt medium (MSL) after the incubation for 28 days showing outstanding potential of isolates.
\end{abstract}

Keywords: Crude oil contamination - Polycyclic aromatic hydrocarbons - Indigenous fungi Biodegradation.

[Cite as: Islam NF (2017) Bioprospecting fungal diversity from crude oil infiltrate soil of Assam, India's Northeast. Tropical Plant Research 4(2): 319-329]

\section{INTRODUCTION}

Crude oil is the most important and predominant energy resource for humans and the raw material of various petroleum products which are essential for daily life. However, during crude oil exploration, a vast amount of drilling mud/fluid is generated (Sarma et al. 2017). Further, oil spills, leaks, and other releases of petroleum products occur frequently during its transportation and result in the contamination of cultivated soil and groundwater, especially when associated with accidental spills (Prasad \& Katiyar 2012). This huge amount of toxic and persistent pollutants like PAHs, HMs, oil, grease, phenols, drilling fluid and mud affect organisms in the biosphere from genetic through molecular levels (Vagi et al. 2005).

Crude oil is a complex mixture of hydrocarbons consisting of saturated hydrocarbons, aromatic hydrocarbons and polar organic compounds. The exploration of crude oil has been by no means without some visible side effects in the ecosystem. The transport of crude oil from point source to various components of the ecosystem is one of the major factors that jeopardize the wellbeing of the environment (Sarma et al. 2016). Oil spillages from drilling sites and oil storage facilities or loading stations are the chief source of contamination of soil or aquatic areas. The term "total petroleum hydrocarbons" (TPH) is generally used to describe the measurable amount of petroleum-based hydrocarbons in the environment. The polycyclic aromatic hydrocarbons (PAHs) present in the crude oil may cause damage to vital organs like lungs, liver, kidneys, intestines and other internal organs and are the major carcinogenic pollutants (Mandal et al. 2012). The biodegradation of these stable compounds are very difficult particularly in case of high molecular weight PAHs compounds. It has been found that the remediation of persistent contaminants such as PAHs from soils is too expensive and time consuming process. Moreover the disposal of these contaminants is posing a serious problem. The most promising and eco-friendly approach for remediation of petroleum hydrocarbon contaminated soil is through biological methods (Mandal et al. 2012).

The biodegradation of crude oil (Uzoamaka et al. 2009, AI-Jawhari 2014) in the environment has been extensively studied and documented in the literature and a large diversity of microorganisms, including bacteria and fungi, are capable of oxidizing or mineralizing a range of $\mathrm{PAH}$ present in the crude oil. Of the microorganisms identified to have the capability to degrade PAHs in the environment, fungi have been shown to 
be relatively more successful in breaking down the higher molecular weight compounds (Potin et al. 2004) than bacteria, principally because of the production of non-specific extracellular enzymes such as laccase, lignin peroxidase and manganese dependent peroxidase $(\mathrm{MnP})$. They also function well in non-aqueous environments where hydrophobic PAHs accumulate; a majority of other microbial degradation occurs in aqueous phase.

The oil industry is one of the major industries in Assam. The main activity of this industry is drilling for exploration and production of oil. The Oil India Limited (OIL) and Oil and Natural Gas Commission (ONGC) are the two leading oil producing companies which are at present actively engaged in crude oil exploration in various sites of Assam. Most of the drilling sites are based at the periphery of the human settlement including agricultural belt causing tremendous health hazards to plants and animals by releasing carcinogenic polyaromatic hydrocarbon of various molecular weight. There is an evidence of heavily contaminated agro ecosystem neighbouring the oil fields of Assam (mainly Digboi, Naharkatia, Rudrasagar, Lakua, Geleki and Borhola, oil fields of upper Assam. Therefore, for effective biodegradation using indigenous organisms are always preferred and research in this area is found to be very scanty in India particularly in the northeastern region. Hence, the present work is based on screening of a set of suitable fungi from crude oil contaminated sites that can be potentially exploited in bioremediation processes.

\section{MATERIALS AND METHODS}

Site location and description

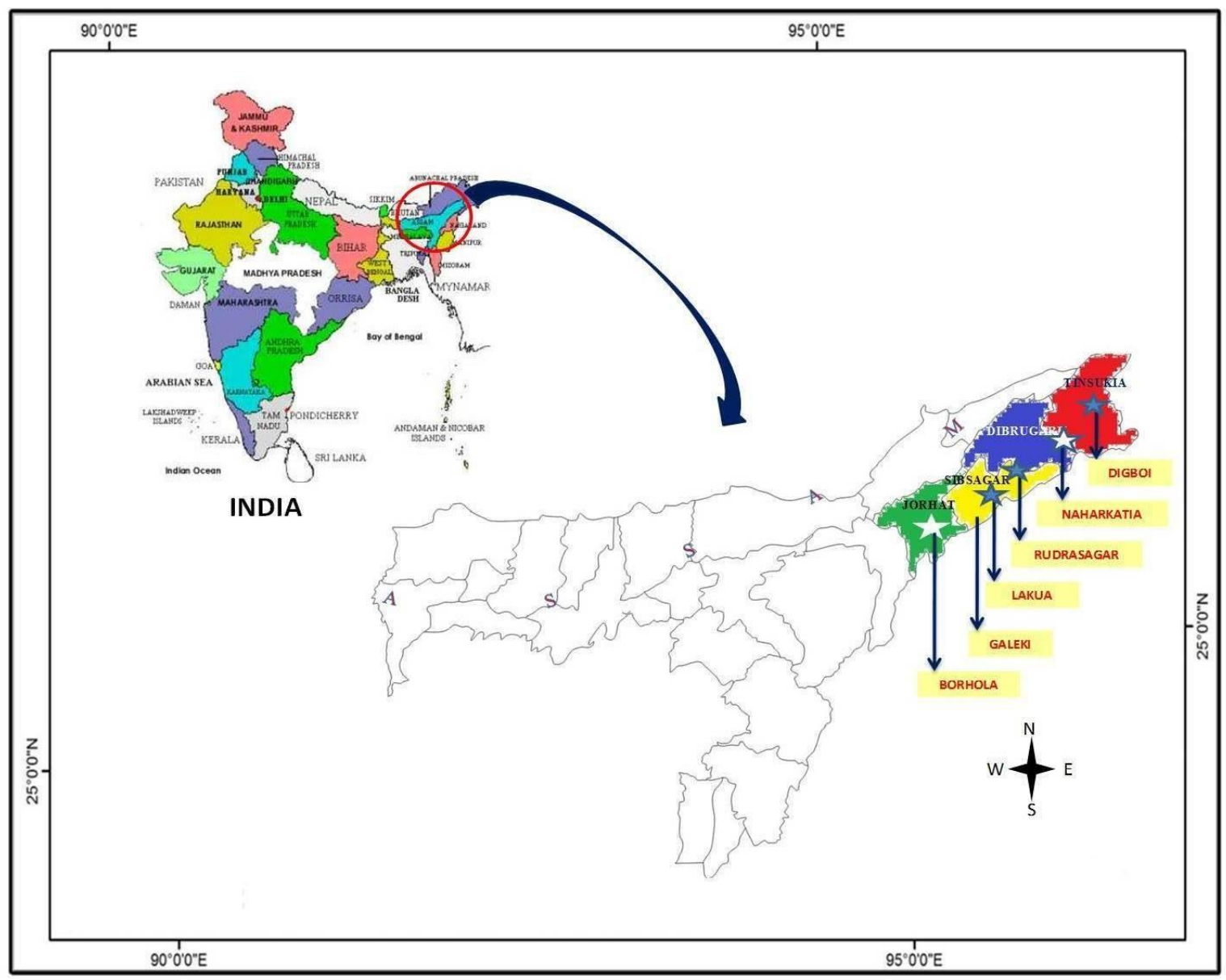

Figure 1. Location map of the study area showing sampling sites.

The study area is located in Assam one of the northeastern states of India (Fig. 1). The area geographically forms part of the Himalayan range. Four districts of Assam comprising of 6 sampling sites viz., Digboi, Naharkatia, Rudrasagar, Lakuwa, Gelakey and Borholla were selected for the study. These are crude oil exploration sites adjacent to which rice fields or tea plantations is predominant, experiencing high level of PAHs contamination. This region is characterized by a humid tropical climate with a mean maximum and minimum temperature of $33.0^{\circ} \mathrm{C}$ and $9^{\circ} \mathrm{C}$ respectively. The average annual rainfall of Assam is $2332 \mathrm{~mm}$. The soils of the study area are of old alluvial type and sandy loam in texture (Table 1). 
Table 1. Physical characteristics of soil.

\begin{tabular}{llllll}
\hline Characteristics & Coarse sand (\%) & Fine sand (\%) & Silt (\%) & Clay (\%) & Textural class \\
\hline Soil test values & 5.39 & 60.24 & 21.22 & 14.73 & Sandy loam \\
\hline
\end{tabular}

Collection of soil samples

Soil samples from the six different contaminated areas were collected aseptically. The soil samples were designated as HC-1, HC-2, HC-3, HC-4, HC-5 and HC-6 for Digboi, Naharkatia, Rudrasagar, Lakuwa, Galeki and Borholla respectively (Table 2). These are the oil exploration and drilling sites of Oil India Limited (OIL) and Oil and Natural Gas Corporation (ONGC) that suffers from moderate to high level of crude oil contaminations at regular intervals due to seepage and other faulty practices (Sarma et al. 2016). The subsurface soil samples $(1-15 \mathrm{~cm})$ contaminated by crude oil were collected randomly from each sites, in sterile dark coloured bottles and poly bags to reduce photo-oxidation and carried to the laboratory. A similar set of soil samples were collected from non-contaminated site as control for comparison. Analysis was commenced immediately upon arrival in the laboratory and samples were refrigerated at $4{ }^{\circ} \mathrm{C}$ until further use.

Table 2. Description of the sampling location of the study area.

\begin{tabular}{|c|c|c|c|c|c|}
\hline S.N. & Site ID & Sampling site & $\begin{array}{l}\text { Geographical } \\
\text { Coordinates }\end{array}$ & $\begin{array}{l}\text { Elevation } \\
\text { (m asl) }\end{array}$ & Category \\
\hline 1. & $\mathrm{HC}-1$ & Digboi & $\begin{array}{l}27^{\circ} 23^{\prime} 35^{\prime \prime} \mathrm{N} \\
95^{\circ} 37^{\prime} 6 " \mathrm{E}\end{array}$ & 157 & Urban and Industrial \\
\hline 2. & $\mathrm{HC}-2$ & Naharkatia & $\begin{array}{l}27^{\circ} 16^{\prime} 55^{\prime \prime} \mathrm{N} \\
95^{\circ} 20^{\prime} 27^{\prime \prime} \mathrm{E}\end{array}$ & 117 & Semi urban/Agricultural \\
\hline 3. & $\mathrm{HC}-3$ & Rudrasagar & $\begin{array}{l}26^{\circ} 58^{\prime} 38^{\prime \prime} \mathrm{N} \\
94^{\circ} 34^{\prime} 52^{\prime \prime} \mathrm{E}\end{array}$ & 92 & Semi urban/Agricultural \\
\hline 4. & $\mathrm{HC}-4$ & Lakua & $\begin{array}{l}26^{\circ} 59^{\prime} 36^{\prime \prime} \mathrm{N} \\
94^{\circ} 49^{\prime} 09^{\prime \prime} \mathrm{E}\end{array}$ & 101 & Semi urban/Agricultural \\
\hline 5. & $\mathrm{HC}-5$ & Galakey & $\begin{array}{l}26^{\circ} 47^{\prime} 24^{\prime \prime} \mathrm{N} \\
94^{\circ} 41^{\prime} 42^{\prime \prime} \mathrm{E}\end{array}$ & 105 & Semi urban/Agricultural and green belt \\
\hline 6. & HC-6 & Borholla & $\begin{array}{l}26^{\circ} 1^{\prime} 50^{\prime \prime} \mathrm{N} \\
93^{\circ} 52^{\prime} 36^{\prime \prime} \mathrm{E}\end{array}$ & 107 & Rural/Agricultural and green belt \\
\hline
\end{tabular}

Analysis of soil chemical properties

Soil $\mathrm{pH}$, organic carbon $(\%)$, available phosphorous $\left(\mathrm{mg} \cdot \mathrm{Kg}^{-1}\right)$, total nitrogen $(\%)$, potassium (ppm), organic matter (\%) and water holding capacity were analysed using standard protocol (Kalra \& Maynard 1991).

\section{Extraction of crude oil from soil}

The extraction of crude oil from soil was carried out using method of AI-Jawhari (2004) with slight modification. Five gram soil sample from each sampling sites was mixed with 1:1 ratio of methylene chloride/acetone solvent and centrifuged at 10,000 rpm for $10 \mathrm{~min}$. The solvent-oil layer was separated from the soil extract and placed in rotary evaporator at $40^{\circ} \mathrm{C}$. After complete evaporation of solvent the amount of oil was measured for gravimetric value.

\section{Isolation of indigenous fungal strains}

Cultivable native fungi were isolated from crude oil contaminated soil. Soil from each site were homogeneously mixed and carefully sorted to remove stones and other unwanted soil debris. $10 \mathrm{~g}$ of soil samples (wet weight) from each site were added to $90 \mathrm{~mL}$ saline solution $[0 \cdot 85 \%(\mathrm{w} / \mathrm{v}) \mathrm{NaCl}]$ in a sterile 250 $\mathrm{mL}$ Erlenmeyer flask, and the solution was suspended by shaking for $5 \mathrm{~min}$ at $150 \mathrm{rev} \mathrm{min}^{-1}$.Further dilution upto to $10^{-6}$ were done in saline solution and plated on Czapek-Dox Agar (CDA) medium containing streptomycin $\left(25 \mu \mathrm{g} \cdot \mathrm{ml}^{-1}\right)$. The plates were incubated at $28-30^{\circ} \mathrm{C}$ for 5 to 7 days. Results were recorded as CFU per gram of soil. The grown cultures were carefully and aseptically sub-cultured onto fresh CDA plates to obtain pure cultures for identification. Altogether, 20 different morphological fungal isolates including one unidentified type, maintained on SDA slant were obtained and identified. The fungal strains were identified on the basis of colonial appearance and microscopic examination of hyphae and spore morphology (Raper \& Thom 1968, Barnett \& Hunter 1972). The abundance of the fungi with respect to different genera was also determined.

Screening of potential isolates based on growth and tolerance to crude oil

Screening of potential fungal isolates was carried out based on their growth and tolerance on medium 
containing crude oil by surface plate assay. To evaluate growth rate of each isolated fungal strain and to test their tolerance to crude oil, discs of agar plug from actively growing fungal culture plates were used. 5-mm disc from colonised Czapek-Dox Agar (CDA) plates was taken from the edge of a fungal colony and placed in the middle of the Potato Dextrose Agar (PDA) medium. Sterile crude oil (1\% w/v) was added to serve as the carbon source through vapour-phase transfer (Raymond et al. 1976). Prior to inoculation, 90-mm diameter discs of sterile cellophane membrane were placed aseptically on the surface of the agar in each Petri dish. The plates without crude oil and inoculated with each of the fungal strains were taken as controls. All treatments were carried out in triplicate and the plates were incubated at $27^{\circ} \mathrm{C}$ for two weeks. The colony radius from the edge of the CDA piece was measured on daily basis in order to access the growth rate of each fungal species.

\section{Biodegradation Studies}

Biodegradation studies were carried out using, $2 \mathrm{~mL}$ of Digboi crude oil (as a sole source of carbon and energy) in $98 \mathrm{~mL}$ mineral salts (MS) medium in $250 \mathrm{ml}$ flasks following the procedure of Uzoamaka et al. (2009) and AI-Jawhari (2014) with minor modification. Mineral salts medium (MSM) was composed of (g. $\mathrm{L}^{-1}$ water) $3 \quad \mathrm{NH}_{4} \mathrm{NO}_{3}, \quad 0.5 \quad \mathrm{KH}_{2} \mathrm{PO}_{4}, 0.5 \quad \mathrm{~K}_{2} \mathrm{HPO}_{4} \cdot 3 \mathrm{H}_{2} \mathrm{O}, 0.008 \quad \mathrm{MgSO}_{4} \cdot 7 \mathrm{H}_{2} \mathrm{O}, 0.002 \mathrm{CuSO}_{4} \cdot 5 \mathrm{H}_{2} \mathrm{O}, 0.002$ $\mathrm{MnSO}_{4} \cdot \mathrm{H}_{2} \mathrm{O}, 0.002 \mathrm{FeSO}_{4} \cdot 7 \mathrm{H}_{2} \mathrm{O}$ and $0.002 \mathrm{CaCl}_{2} \cdot 2 \mathrm{H}_{2} \mathrm{O}$ (Jia et al. 2008). The pH was adjusted to 7.5 with either $\mathrm{HCl}$ or $\mathrm{NaOH}$ solutions. $5 \mathrm{~mm}$ disk from each of the seven potential strains (Aspergillus terreus, Cunninghamella elegans, Aspergillus flavus, A. versicolor, A. fumigatus, A. niger and Trichoderma harzianum) of 7 days old pure culture were inoculated separately in $250 \mathrm{~mL}$ flasks containing MS medium and incubated at $27^{\circ} \mathrm{C}$ for a period of 28 days. The control flasks without organisms were prepared accordingly. All treatments were carried out in triplicate. $5 \mathrm{~mL}$ of culture broth from each flask were collected at a regular interval of 7 days and subjected to centrifugation $(10,000 \mathrm{rpm})$ to obtain cell free supernatant. The estimation of crude oil degradation was determined by gravimetric method. For separation of residual crude oil in the culture supernatant, $5 \mathrm{~mL}$ of $\mathrm{n}$-hexane was used in a separating funnel. The solvent extraction was carried out twice for complete recovery of oil. Hexane was evaporated in a hot air oven $\left(50^{\circ} \mathrm{C}\right)$ and the residual oil obtained was weighed. The percentage degradation of the crude oil was determined as described by the equation, \% Degradation $=\frac{\mathrm{a}-\mathrm{b}}{\mathrm{a}} \times 100$, where ' $\mathrm{a}$ ' is the initial weight of undegraded crude oil (control), ' $\mathrm{b}$ ' is the weight of the remaining crude oil after degradation.

\section{Statistical data analysis}

All the data were examined for significant differences between treatments using analysis of variance (ANOVA). To establish if differences between individual treatments were significant $(P<0.05)$ the test for least significant differences and least information criterion was used (SPSS version 24).Correlation between various components were analyzed. P values $<0.01$ and $<0.05$ were considered as significant. Variance components like coefficient of variations were also calculated. Means were separated with Duncan Multiple Range Test (DMRT) in respective tables.

\section{RESULTS}

Soil chemical properties

Table 3. Chemical properties contaminated soil.

\begin{tabular}{lrrrrrr}
\hline Soil parameters & HC-1 & HC-2 & HC-3 & HC-4 & HC-5 & HC-6 \\
\hline $\mathrm{pH}$ & 6.21 & 6.13 & 5.03 & 6.15 & 5.98 & 6.01 \\
Soil organic carbon (\%) & 3.16 & 3.24 & 2.56 & 1.65 & 3.96 & 3.82 \\
Available phosphorus (mg.kg ${ }^{-1}$ ) & 3.6 & 1.5 & 5.5 & 5.8 & 4.09 & 3.9 \\
Total nitrogen (\%) & 0.03 & 0.17 & 0.68 & 0.55 & 0.04 & 0.07 \\
Potassium (ppm) & 145 & 132 & 162 & 146 & 180 & 132 \\
Organic matter (\%) & 4.33 & 5.11 & 4.30 & 3.25 & 6.04 & 6.22 \\
Water holding capacity & 56.36 & 60.18 & 64.12 & 52.28 & 58.60 & 55.18 \\
\hline Note: Value are mean of + standard deviation of $(\mathrm{n}=5)$ & & & & &
\end{tabular}

The crude oil degradation processes is reported to be affected by multifarious factors. Some of the important ones are biological factors, nutrients availability, soil $\mathrm{pH}$ and degree of contaminations by petroleum hydrocarbons. The results of the soil chemical parameters are shown in the Table 3 . The result ranged as follows: $\mathrm{pH}, 5.03-6.21$; soil organic carbon, 1.65 to $3.96 \%$; Available phosphorus 1.5 to $5.8 \mathrm{mg} . \mathrm{kg}^{-1}$; Total nitrogen 0.03 to $0.68 \%$; Potassium 132 to 180 ppm; Organic matter 3.25 to $6.22 \%$. 


\section{Extraction of crude oil from soil}

Extraction of crude oil from all the six contaminated soils showed significant variations. The extractable crude oil ranged from $39000 \mathrm{mg} . \mathrm{Kg}^{-1}$ to $51500 \mathrm{mg} . \mathrm{Kg}^{-1}$ of contaminated soil (Fig. 2). The highest concentration (51500 mg. $\mathrm{Kg}^{-1}$ ) was recorded from site HC-6. The spatial variations of crude oil across the sampling sites showed significant variations [F (2.256), P < 0.05] based on linear independent pair wise comparison. The least information criteria of distribution of petroleum hydrocarbons according to the Akaike's information criterion and Hurvich and Tsai's criterion was [(721.813) $(\mathrm{R} 2=0.84)]$.

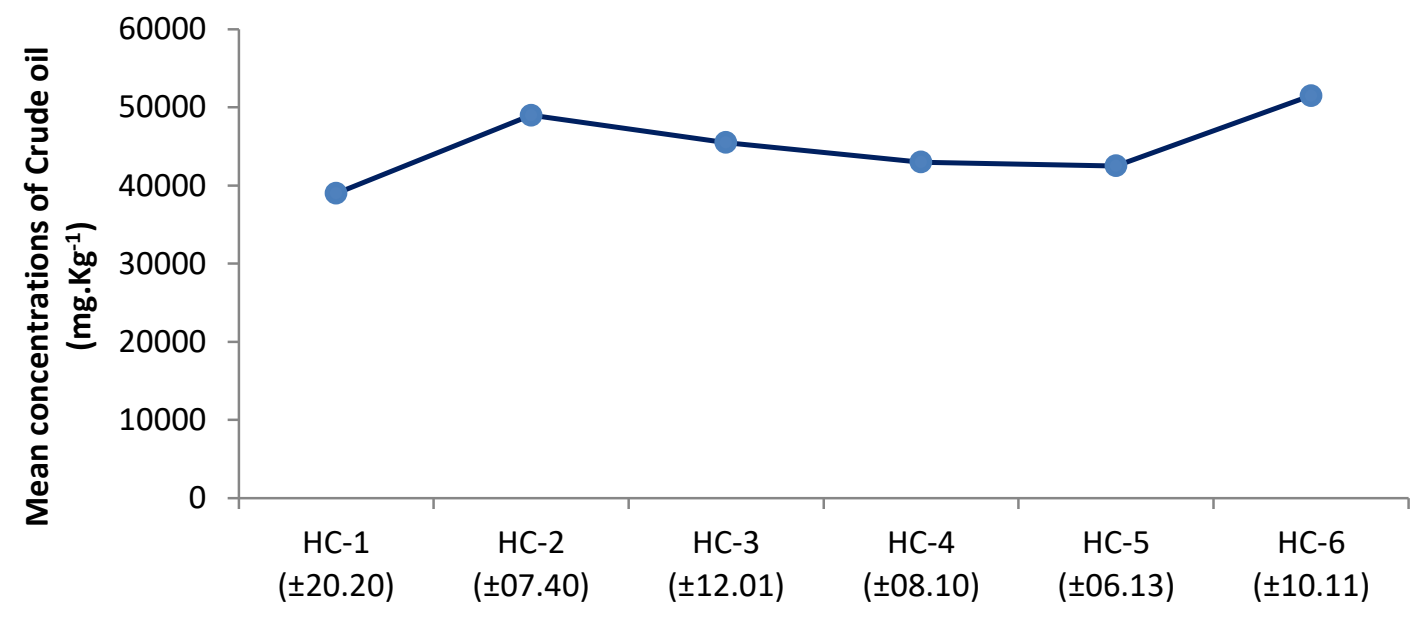

Sampling sites

Figure 2. Concentrations of Crude oil in the sampling sites. (Values in the parentheses denote Standard deviation across the mean).

\section{Isolation of indigenous fungal strains}

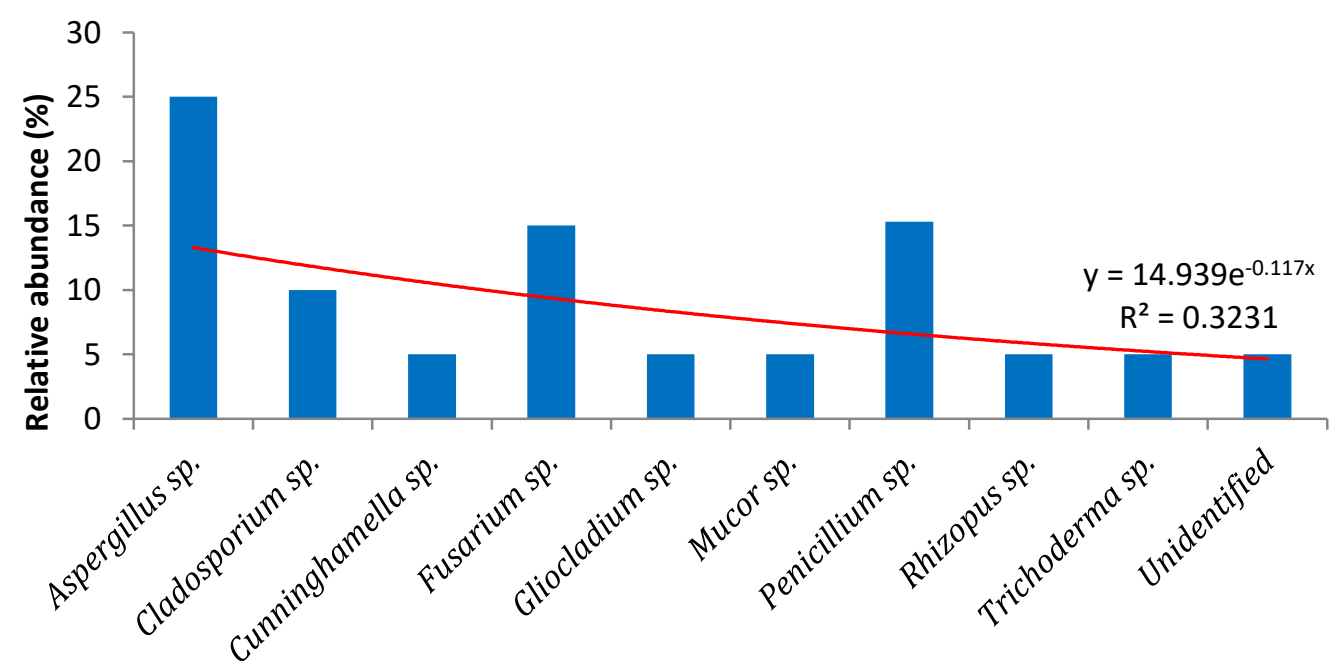

Figure 3. Relative abundance of fungal genera.

A total of 20 fungal isolates including one unidentified were obtained from crude oil-contaminated soils. The morphological identification of the fungal strains showed that they belong to 9 genus with typical structures of Aspergillus (5 species), Cladosporium (2 species), Cunninghamella (1 species), Fusarium (3 species), Gliocladium (1 species), Mucor (1 species), Penicillium (4 species), Rhizopus (1 species) and Trichoderma (1 species). The relative abundance of fungal genera is shown in the figure 3 . The most dominant genus is Aspergillus (25\%) followed by Penicillium (15.3\%) and Fusarium (15\%). The fungal population was highest in the soil sample collected from HC-5 $\left(19.2 \times 10^{6} \mathrm{CFU} . \mathrm{g}^{-1}\right.$ soil) and HC-6 $\left(17.7 \times 10^{6} \mathrm{CFU} . \mathrm{g}^{-1}\right.$ soil), and lowest in HC-1 $\left(14.6 \times 10^{6} \mathrm{CFU}_{\mathrm{g}}{ }^{-1}\right.$ soil). In the other three sampling sites the count is almost similar varying from $15.2 \times 10^{6} \mathrm{CFU} . \mathrm{g}^{-1}$ soil to $16.6 \times 10^{6} \mathrm{CFU}_{\mathrm{g}}{ }^{-1}$ soil. The dominant species among the fungal population across all the sites were Aspergillus fumigates $\left(11.6 \times 10^{6} \mathrm{CFU} . \mathrm{g}^{-1}\right.$ soil) and Aspergillus terreus (10.76) (Table 4). 
Table 4. Fungal population $\left(\mathrm{CFU} \mathrm{g} \mathrm{g}^{-1} 10^{6}\right)$ isolated from different crude oil contaminated sites.

\begin{tabular}{lcrrrrrr}
\hline Fungal species & Strain ID & HC-1 & HC-2 & HC-3 & HC-4 & HC-5 & HC-6 \\
\hline Aspergillus flavus & NF1 & 2.6 & 2.7 & 0.7 & 2.9 & 1.7 & 1.0 \\
A. fumigatus & NF2 & - & 0.02 & 1.6 & 1.8 & - & 2.7 \\
A. niger & NF3 & 0.09 & 0.03 & 1.5 & 1.2 & 0.7 & 0.1 \\
A. versicolor & NF4 & 0.06 & 0.7 & 1.8 & 0.6 & 0.08 & 1.7 \\
A. Terreus & NF5 & 1.1 & 1.6 & 0.06 & 2.7 & 2.8 & 2.5 \\
Cladosporium cladosporioides & NF6 & 0.2 & 1.5 & - & 0.9 & 3.0 & 2.0 \\
C. resinae & NF7 & - & 0.8 & - & 1.7 & 2.6 & 2.5 \\
Cunninghamella elegans & NF8 & 1.4 & 2.3 & 2.4 & 0.13 & 0.02 & - \\
Fusarium equiseti & NF9 & 2.5 & - & - & 0.6 & 1.7 & 1.2 \\
F. oxysporum & NF10 & - & 0.3 & 1.2 & 0.1 & - & - \\
F. solani & NF11 & - & 0.7 & 0.4 & 2.0 & 2.6 & \\
Gliocladium viride & NF12 & 0.01 & 0.07 & 1.2 & 0.09 & - & 0.5 \\
Mucor racemosus & NF13 & 2.0 & 1.3 & 1.8 & 1.0 & - & 1.5 \\
Penicillium citrinum & NF14 & 0.09 & - & 1.4 & 0.03 & 2.0 & 0.06 \\
$P$. commune & NF15 & - & 0.5 & 1.2 & 0.01 & - & - \\
$P$. funiculosum & NF16 & - & 1.2 & - & - & - & 0.08 \\
$P$. glabrum & NF17 & 0.9 & 0.04 & - & - & - & 0.03 \\
Rhizopus stolonifer & NF18 & 0.8 & - & 1.0 & 0.01 & 0.08 & - \\
Trichoderma harzianum & NF19 & 1.8 & 2.1 & 0.3 & 0.4 & 1.0 & 1.1 \\
Unidentified & UI & 1.0 & 0.3 & 0.04 & - & 0.9 & 0.6 \\
\hline
\end{tabular}

Screening of potential isolates based on growth and tolerance to crude oil

The growth rates of different fungal isolates in the presence of crude oil in surface plate assays are shown in table 5. Mycelial extension rates exhibited significant differences between the strains with respect to their growth ability in the presence or absence of $1 \%$ (w/v) crude oil for two weeks. Species of Aspergillus, Cunninghamella and Trichoderma did not show any significant inhibitory effect. Species of Penicillium were the most sensitive isolates (50.4-99.9\% sensitivity) as the rate of growth notably decreased in the presence of the crude oil. The most tolerant species to crude oil was Aspergillus terreus showing $0.50 \mathrm{~cm} . \mathrm{d}^{-1}$ of radial growth compared to control $\left(0.44 \mathrm{~cm} \cdot \mathrm{d}^{-1}\right)(P<0.05)$. This is followed by Cunninghamella elegans $\left(0.41 \mathrm{~cm} . \mathrm{d}^{-1}\right)$, Aspergillus flavus $\left(0.40 \mathrm{~cm} . \mathrm{d}^{-1}\right)$, A. versicolor $\left(0.39 \mathrm{~cm} . \mathrm{d}^{-1}\right)$, A. fumigatus $\left(0.38 \mathrm{~cm} . \mathrm{d}^{-1}\right)$, A. niger $\left(0.30 \mathrm{~cm} . \mathrm{d}^{-1}\right)$ and Trichoderma harzianum $\left(0.29 \mathrm{~cm} . \mathrm{d}^{-1}\right)$ on the surface of crude oil. The slowest growth rate was exhibited by Penicillium commune $\left(0.03 \mathrm{~cm}^{-1}\right)$. The significant $\left(\mathrm{R}^{2}=0.90, \mathrm{P}<0.05\right)$ increase in the growth of Aspergillus terreus and Cunninghamella elegans in the presence of crude oil suggests that they can better utilize it as a growth substrate.

Table 5. Radial extension rate $\left(\mathrm{cm} \cdot \mathrm{d}^{-1}\right)$ of fungal isolates in presence of crude oil.

\begin{tabular}{lcrr}
\hline Isolate & Strain ID & Control & Crude oil treatment \\
\hline Aspergillus flavus & NF1 & $0.409( \pm 0.09)$ & $0.401( \pm 0.09)$ \\
A. fumigatus & NF2 & $0.404( \pm 0.02)$ & $0.388( \pm 0.004)$ \\
A. niger & NF3 & $0.330( \pm 0.01)$ & $0.300( \pm 0.03)$ \\
A. versicolor & NF4 & $0.385( \pm 0.08)$ & $0.398( \pm(0.02)$ \\
A. Terreus & NF5 & $0.446( \pm 0.009)$ & $0.500( \pm 0.01)$ \\
Cladosporium cladosporioides & NF6 & $0.191( \pm 0.02)$ & $0.105( \pm 0.01)$ \\
C. resinae & NF7 & $0.132( \pm 0.01)$ & $0.102( \pm 0.001)$ \\
Cunninghamella elegans & NF8 & $0.408( \pm 0.008)$ & $0.418( \pm 0.04)$ \\
Fusarium equiseti & NF9 & $0.211( \pm 0.03)$ & $0.108( \pm 0.01)$ \\
F. oxysporum & NF10 & $0.115( \pm 0.01)$ & $0.098( \pm 0.01)$ \\
F. solani & NF11 & $0.203( \pm 0.04)$ & $0.109( \pm 0.01)$ \\
Gliocladium viride & NF12 & $0.205( \pm 0.03)$ & $0.170( \pm 0.01)$ \\
Mucor racemosus & NF13 & $0.100( \pm 0.01)$ & $0.067( \pm 0.03$ \\
Penicillium citrinum & NF14 & $0.222( \pm 0.02)$ & $0.110( \pm 0.007)$ \\
$P$. commune & NF15 & $0.113( \pm 0.03)$ & $0.030( \pm(0.001)$ \\
$P$. funiculosum & NF16 & $0.150( \pm 0.06)$ & $0.076( \pm 0.005)$ \\
$P$. glabrum & NF17 & $0.145( \pm 0.05)$ & $0.047( \pm 0.004)$ \\
Rhizopus stolonifer & NF18 & $0.196( \pm 0.06)$ & $0.101( \pm 0.01)$ \\
Trichoderma harzianum & NF19 & $0.298( \pm 0.05)$ & $0.291( \pm 0.03)$ \\
Unidentified & UI & $0.156( \pm 0.02)$ & $0.089( \pm 0.002)$ \\
\hline
\end{tabular}

Note: Values in the parentheses shows standard deviation from mean, $\mathrm{n}=3$. 
Biodegradation Studies

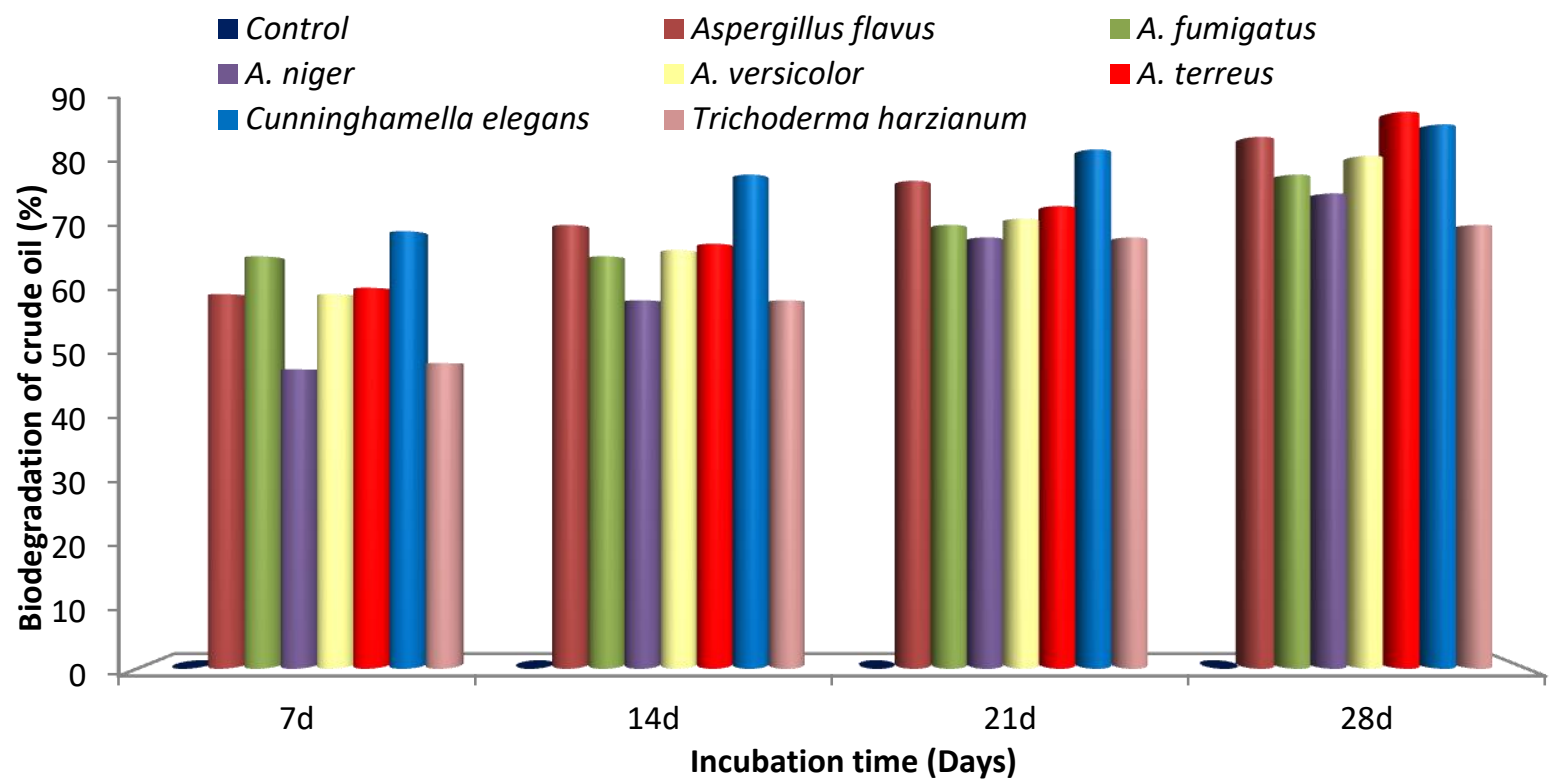

Figure 4. Biodegradation of crude oil by selected fungi.

Out of the 20 fungal isolates only seven of them showed their ability to degrade crude oil contaminant (Fig. $4)$. The potential fungal strains were tested based on their ability to degrade crude oil when grown in mineral salt medium for 28 days. The highest degradation of crude oil after 28 days of incubation was observed with Aspergillus terreus (89\%) and Cunninghamella elegans (87\%) followed by Aspergillus flavus (85\%), A. versicolor (82\%), A. fumigatus (79\%), A. niger (76\%) and Trichoderma harzianum (71\%) respectively. A. flavus, A. fumigatus, A. versicolor, A. terreus and Cunninghamella elegans showed more than $60 \%$ degradation within 7 days of incubation. There was positive correlation between the crude oil degrading ability of the fungi (Fig. 5) and the growth rate of the fungi.

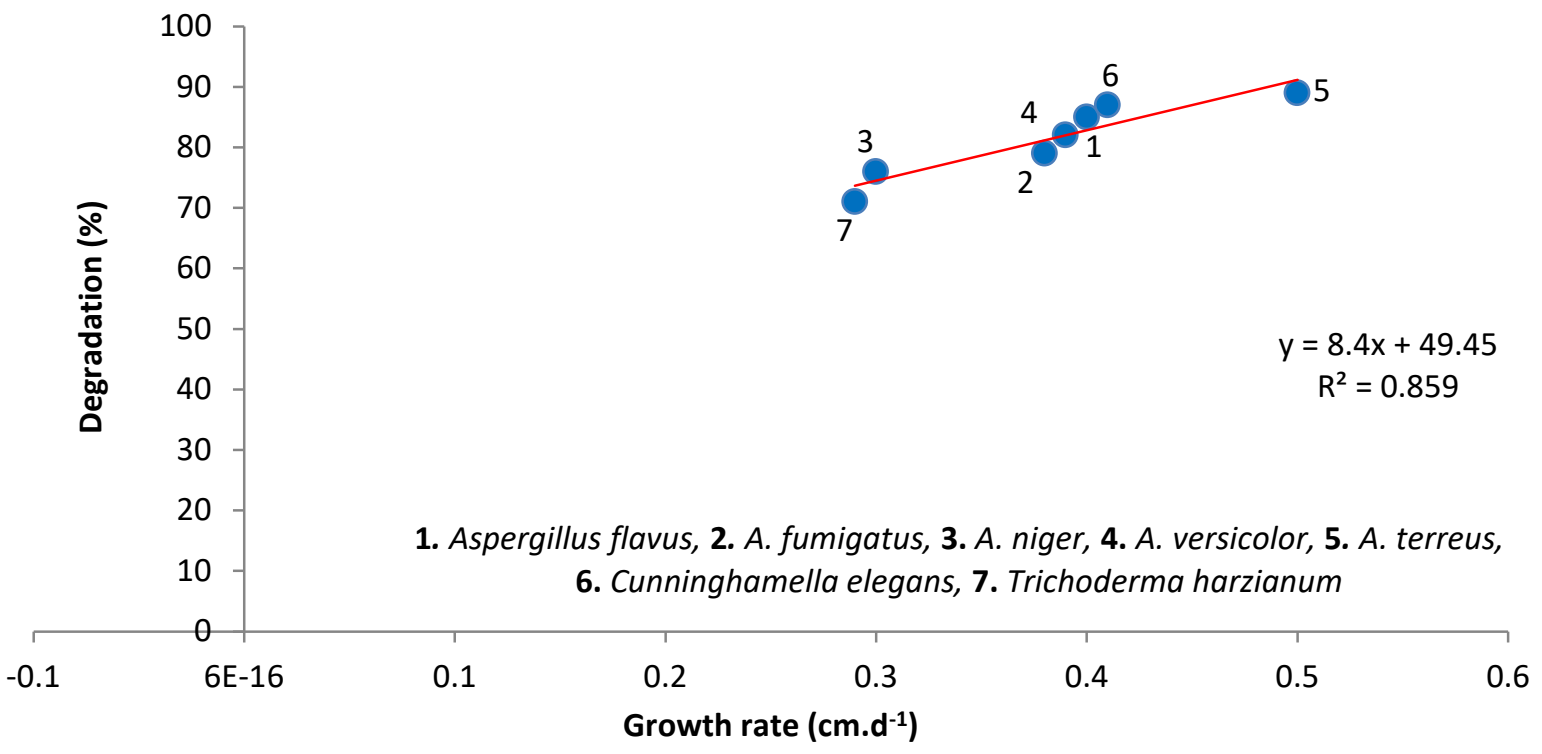

Figure 5. Correlation between crude oil degrading ability and growth rate of seven different fungal isolates.

\section{DISCUSSION}

In the present study soil parameters like $\mathrm{pH}$, Soil organic carbon, phosphorus, nitrogen, potassium, organic matter and water holding capacity, from contaminated sites were assessed to determine its effect on fungal population to biodegrade petroleum hydrocarbons of crude oil (Fierer \& Jackson 2006). The high soil pH in the present study may be due to disparity in leaching of essential salts due to presence of petroleum hydrocarbons. Hydrocarbon degradation has been reported to be favoured in slightly alkaline soils (Maeir et al.2000). In the www.tropicalplantresearch.com 
present study four out of six sampling sites showed $\mathrm{pH}$ above 6 and $\mathrm{pH}$ range between 6 to 8 has been suggested conducive for bioremediation. The organic carbon content and total nitrogen of the polluted soils was in the range of 1.65 to $3.96 \%$ and 0.03 to $0.68 \%$. This may be attributed to the steady input of petroleum hydrocarbons. The soil phosphorus was in the range of 1.5 to $5.8 \mathrm{mg} \cdot \mathrm{Kg}^{-1}$. The optimum C:N:P ratio in soil is critical for biodegradation of petroleum hydrocarbon as microorganisms utilize these elements for incorporation into biomass and the synthesis of cellular components (Atlas \& Bartha 1992, Stroud et al. 2007). The water holding capacity or the presence of moisture level is one of the essential parameters for the biodegradation of crude oil at the optimum level. Low soil moisture may impede the microbial activity by affecting the petroleum hydrocarbon transport and bioavailability (Sarma et al. 2016). The water holding capacity in the present study is between 52 to $64 \%$ which was at par to the earlier finding (Vadali 2001).

The amount of crude oil in soil is largely dependent on soil physical, chemical or biological processes The removal of crude oil from the soil depends on soil type, soil organic matter content, soil minerals, the physicochemical properties of the individual PAH, soil temperature and moisture, redox potential, nutrients availability, presence and activity of degrading microorganisms and bioavailability of the PAH to degrading microorganisms (Meijer et al. 2002, Nam et al. 2008, Okere \& Semple 2012). The variations in the amount of crude oil may be due to leaching phenomenon, volatilization or photo-oxidation (Wilcke et al. 1999). These variations were also dependent on the distance from the source of pollution and the prevailing climatic conditions (Wild \& Jones 1995). The amount of crude oil in the soil can be used to estimate the sources of pollution. The levels of crude oil in the spilled soils are similar to levels reported earlier (Cheraghi et al. 2015).

A total of 20 fungal isolates were initially obtained from CDA medium. Of these, 7 potential isolates were screened based on ability to degrade crude oil. The potentials fungal strains were identified as Aspergillus terreus, Cunninghamella elegans, A. versicolor, A. flavus, A. fumigatus, A.niger and Trichoderma harzianum. Some of these fungi have been reported earlier as hydrocarbon bio-degraders (Uzoamaka et al. 2009). The fungal population in the contaminated sites varied from $17.7 \times 10^{6} \mathrm{CFU} . \mathrm{g}^{-1}$ soil to $19.2 \times 10^{6} \mathrm{CFU}_{\mathrm{g}} \mathrm{g}^{-1}$ soil. Low CFU count in some of the sites may be due to low moisture contents which might be responsible for the inhibition of fungal growth. The result is in consistence with the previous findings (Sims \& Overcash 1983, Yuan et. al. 2001).

An increasing trend in the fungal population with the increase in crude oil contamination has been observed in some of the experimental sites. The results clearly demonstrated the positive relationship between the crude oil contents and the fungal population in the contaminated soils. The present results contradict the findings of Sims \& Overcash (1983) who demonstrated that the higher concentration of PAH in the soil retards the depletion of PAHs by microbes due to high level of PAHs toxicity. Increased fungal population may be due to high $\mathrm{pH}$ and moisture and their adaptability to the prevailing environmental conditions (Rahman et al. 2002).The isolated fungal population might have the potentiality to assimilate petroleum hydrocarbon in the contaminated soil. The growing trend in the fungal population with the increase in petroleum hydrocarbon compounds has been also discussed by different researchers (Shi et al. 2002). Similarly, in some of the earlier studies, large population of bacteria, actinomycetes and fungi were recorded from oil-spilled environment (Venkateswaran et al. 1993, Wrenn \& Venosa 1996, Cabello 1997).

In the present study screening of potential fungal isolates was based on their ability to grow on crude oil by surface plate assay. The method proved to be advantageous over other traditional methods used to screen hydrocarbon degrading strains, as the degradation is directly correlated to growth and metabolism of the fungi growing on hydrocarbon substrates using it as the source of carbon and energy. The increment and reduction in growth among different fungal isolates was due to varying degree of tolerance to crude oil. The isolated crude oil degraders belong to the genera Aspergillus, Cladosporium, Cunninghamella, Fusarium, Gliocladium, Mucor, Penicillium, Rhizopus and Trichoderma. The most tolerant species to crude oil as noted in the present study was Aspergillus terreus.

Biodegradation of crude oil is a crucial process involving different soil microbial population. The role of some of these microorganisms have been extensively reviewed (Shuttleworth \& Cerniglia 1995, Macleod et al. 2001, Macleod \& Semple 2002, Zhang et al. 2006, Peng et al. 2008). Most of the works were confined to the degrading ability of bacteria and as such development of suitable mycoremediation strategies using potential fungal strains is a real challenge. The growth and distribution of crude oil degrading microbial populations depends on environmental conditions (Margesin \& Schinner 2001), soil properties (Manilal \& Alexander 1991), bioavailability of the PAH (Ogram et al. 1985) and presence or absence of compounds toxic to microbes (Sarma www.tropicalplantresearch.com 
et al. 2017). Thus lack of tolerance of microbial population to these factors may lead to persistence of petroleum hydrocarbons in contaminated soils. In the present study, 20 fungal isolates were obtained from different crude oil-contaminated soils however only seven of them were found to be as potential candidates to degrade crude oil contamination. This is exemplified by their capacity to grow over crude oil layer viz., Aspergillus terreus, Cunninghamella elegans, Aspergillus versicolor, A. flavus, A. fumigatus, A. niger and Trichoderma harzianum. In the present study, species of Aspergillus showed maximum degrading ability, which may be due to their better adaptability to crude oil contamination sites. The observations are in consonance with the previous findings (Uzoamaka et al. 2009). The role of some of these fungi in degradation of different hydrocarbons has been described elsewhere by different workers (Massaccesi et al. 2002); however the data is insufficient on their growth rate and range of tolerance to crude oil. The variability of fungal isolates in the present findings may be due to different degree of crude oil contamination, their range of tolerance with respect to sites and seasonal impact. Moreover, variations in soil parameter like $\mathrm{pH}$, moisture and organic matter have profound effect on their distribution. Thus the types of exposure largely determine the ability of indigenous fungi to degrade crude oil contaminated soils. As most of the researches were focused on the degradation of crude oil by various biological, chemical and physiological processes, the ability of fungi needs attention as because fungi have more tolerance to crude oil. The use of highly tolerant fungal isolates could boost up the degradation process.

\section{CONCLUSION}

This work demonstrated that the seven out of twenty isolated fungi from the crude oil contaminated environment exhibited exceptional ability in degrading crude oil. The preliminary findings indicated that these fungi have higher tolerance potential than other tested fungal strain which makes them more attractive potential candidates for further investigations regarding their ability to remove crude oil from contaminated sites.

\section{ACKNOWLEDGMENT}

The author is grateful to University Grant Commission, Governmentof India for financial support (Grant No. F.5-53/2014-15/MRP/NERO/1683 dated 05 ${ }^{\text {th }}$ Feb, 2015) and to Dr. Hemen Sarma, N.N. Saikia College for technical support.

\section{REFERENCES}

AI-Jawhari IFH (2014) Ability of Some Soil Fungi in Biodegradation of Petroleum Hydrocarbon Journal of Applied and Environmental Microbiology 2: 46-52.

Atlas RM \& Bartha R (1992) Hydrocarbon biodegradation and oil-spill bioremediation. Advances in Microbial Ecology 12: 287-338.

Barnett HL \& Hunter BB (1972) Illustrated Genera of Imperfect Fungi. Burgess Publishing Co. Minneapolis. $241 \mathrm{p}$.

Cabello MN (1997) Hydrocarbon pollution: its effect on native arbuscular mycorrhizal fungi (AMF). FEMS Microbiology Ecology 22: 233-236.

Cheraghi M, Sobhanardakani S, Lorestani B, Merrikhpour H \& Mosaed H P (2015) Biochemical and Physical Characterization of Petroleum Hydrocarbon Contaminated Soils in Tehran. Journal of Chemical Health Risks 5(3): 199-208.

Fierer N \& Jackson RB (2006) The diversity and biogeography of soil bacterial communities. Proceedings of the National Academy of Science USA 103: 626-631.

Jia Y, Yin H, Ye J S, Peng H, He B Y, Qin H M, Zhang N \& Qiang J (2008) Characteristics and pathway of naphthalene degradation by Pseudomonas sp. N7. Environmental Science and Technology 29: 756-762.

Kalra YP \& Maynard DG (1991) Methods manual for forest soil and plant analysis. Information report NOR-X319. Northern Forestry Centre, Northwest Region, Forestry Canada, Edmonton, Alberta. Information Report NOR-X-319.

Macleod CJ, Morriss AW \& Semple KT (2001) The role of microorganisms in ecological risk assessment of hydrophobic organic contaminants in soils. Advances in Applied Microbiology 48: 171-212.

Macleod CJ \& Semple KT (2002) The adaptation of two similar soils to pyrene catabolism. Environmental Pollution 119: 357-364.

Maeir RM, Pepper IL \& Gerba PC (2000) A textbook of environmental microbiology. Academic press San Diego, CA., 624 p. 
Mandal AK, Sarma PM, Jeyaseelan CP, Channashettar VA, Singh B, Lal B \& Datta J (2012) Large scale bioremediation of petroleum hydrocarbon contaminated waste at Indian oil refineries: case studies. International Journal of Life Science and Pharma Research 2(4): 114-128.

Manilal VB \& Alexander M (1991) Factors affecting the microbial degradation of phenanthrene in soil. Applied Microbiology and Biotechnology 35: 401-405.

Margesin R \& Schinner F (2001) Biodegradation and bioremediation of hydrocarbons in extreme environments. Applied Microbiology and Biotechnology 56: 650-663.

Massaccesi G, Romero MC, Cazau MC \& Bucsinszky AM (2002) Cadmium removal capacities of filamentous soil fungi isolated from industrially polluted sediments in La Plata (Argentina). World Journal of Microbiolial Biotechnology18: 817-820.

Meijer S N, Steinnes E, Ockenden WA \& Jones KC (2002) Influence of environmental variables on the spatial distribution of PCBs in Norwegian and U.K. soils: implications for global cycling. Environmental Science and Technology 36: 2146-2153.

Nam J J, Thomas G O, Jaward FM, Steinnes E \& Gustafsson O (2008) PAHs in background soils from Western Europe: influence of atmospheric deposition and soil organic matter. Chemosphere 70: 1596-1602.

Ogram AV, Jessup R E, Ou L T \& Rao P S (1985) Effects of sorption on biological degradation rates of $(2,4-$ dichlorophenoxy) acetic acid in soils. Applied Environmental Microbiology 49: 582-587.

Okere UV \& Semple KT (2012) Biodegradation of PAHs in 'Pristine' Soils from Different Climatic Regions. Journal of Bioremediation and Biodegradation S1: 006. [doi:10.4172/2155-6199.S1-006]

Peng RH, Xiong AS, Xue Y, Fu XY \& Gao F (2008) Microbial biodegradation of polyaromatic hydrocarbons. FEMS Microbiolical Review 32: 927-955.

Potin O, Veignie E \& Rafin C (2004) "Biodegradation of polycyclic aromatic hydrocarbon (PAHs) contaminated soil”. FEMS Microbiology Ecology 51: 71.

Prasad MNV \& Katiyar SC (2012) Drill cuttings and fluids of fossil fuel exploration in north-eastern India: environmental concern and mitigation options. Current Science 98(12): 1566-1569.

Rahman PKSM, Rahman TJ, Lakshmanaperumalsamy P \& Banat IM (2002) Occurrence of crude oil degrading bacteria in gasoline and diesel station soils. Journal of Basic Microbiology 42 (4): 284-291.

Raper KB \& Thom C (1968) A Manual of the Penicillia. Hafner Publishing Co. New York., 875 p.

Raymond RL, Audson JO \& Jamison VW (1976) Oil degradation in soil. Applied Environmental Microbiology 31: 522-535.

Sarma H, Islam NF, Borgohain P, Sarma A \& Prasad MNV (2016) Localization of polycyclic aromatic hydrocarbons and heavy metals in surface soil of Asia's oldest oil and gas drilling site in Assam, northeast India: Implications for the bio-economy. Emerging Contaminants 2: 119-127.

Sarma H, Islam NF \& Prasad MNV (2017) Plant-microbial-association in petroleum and gas exploration sites in Assam, Northeast-Indian State significance for remediation. Environmental Science Pollution Research 24(9): 8744-8758

Shi W, Becker J, Bischoff M, Turco RF \& Konopka AE (2002) Association of Microbial Community Composition and Activity with Lead, Chromium, and Hydrocarbon Contamination. Applied and Environmental Microbiology 68(8): 3859-3866.

Shuttleworth KL \& Cerniglia CE (1995) Environmental aspects of PAH biodegradation. Applied Biochemistry and Biotechnology 54: 291-302.

Sims RC \& Overcash MR (1983) Fate of polynuclear aromatic compounds (PNAs) in soil-plant systems. Research Review 88: 1-67.

Stroud JL, Paton GI \& Semple KT (2007) Microbe-aliphatic hydrocarbon interactions in soil: implications for biodegradation and bioremediation. Journal of Applied Microbiology 102: 1239-1253.

Uzoamaka GO, Floretta T \& Florence MO (2009) Hydrocarbon Degradation Potentials of Indigenous Fungal Isolates from Petroleum Contaminated Soils. Journal of Physical and Natural Sciences 3(1): 1-6.

Vadali M (2001) Bioremediation. An overview. Pure and Applied Chemistry 73: 1163-1172.

Vagi MC, Kostopoulou MN, Petsas AS, Lalousi ME, Rasouli Ch \& Lekkas TD (2005) Toxicity of organophoshorous pesticides to the marine alga Tetraselmis suecica. Global NEST Journal 7 (2): 222-227.

Venkateswaran K, Kanai S, Tanaka H \& Miyachi S (1993) Vertical distribution and biodegradation activity of oil degrading bacteria in the Pacific Ocean. Journal of Marine Biotechnology 1: 33-39. 
Wilcke W, Müller S, Kanchanakool, Niamskul C \& Zech W (1999) Polycyclic aromatic hydrocarbons in hydromorphic soils of the tropical metropolis Bangkok. Geoderma 91: 297-309.

Wild SR \& Jones KC (1995) Polynuclear aromatic hydrocarbons in the United Kingdom environment: a preliminary source inventory and budget. Environmental Pollution 88: 91-108.

Wrenn BA \& Venosa AD (1996) Selective enumeration of aromatic and aliphatic hydrocarbon degrading bacteria by a most probable number procedure. Canadian Journal of Microbiology 42: 252-258.

Yuan SY, Wei SH \& Chang BV (2001) Biodegradation of polycyclic aromatic hydrocarbons by a mixed culture. Chemosphere 41: 1463.

Zhang XX, Cheng SP, Zhu CJ \& Sun SL (2006) Microbial PAH-degradation in soil: degradation pathways and contributing factors. Pedosphere 16: 555-565. 